\title{
Effect of muscle energy technique in treating post-partum coccydynia: A randomized control trial
}

Heba Embaby', Salwa Elgendy² and Marwa Esmael Hasanin ${ }^{1 *}$

*Correspondence: dr_marwa_esmael@hotmail.com

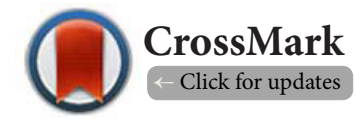

'Lecturer in the department of Physical Therapy for Obstetrics and Gynecology, Faculty of Physical Therapy, Cairo University, Egypt. ${ }^{2}$ Associate professor in the department of Physical Therapy, Faculty of Applied Medical Sciences, King Abdulaziz University, Jeddah.

\begin{abstract}
Background: Coccydynia is a pain in the coccyx. It mainly affects females. Approximately $14 \%$ of coccydynia occurs due to delivery trauma. Muscle Energy Technique (MET) is mainly used to treat the musculoskeletal disorders. The effect of MET in gynecological disorders is not clear yet.

Objective: This study was an attempt to determine effect of MET in treating post-partum coccydynia.

Participants and method: Forty multi-parus females, suffering from coccydynia after 6 weeks postpartum participated in this study. Their ages ranged from (25-35) years, parity (3-5) and their body mass index did not exceed $35 \mathrm{Kg} / \mathrm{m}^{2}$. They were randomly divided into two equal groups. The study group (A) received MET with phonophoresis (PP) and home programme based on MET for four weeks, 3 sessions per week. The control group (B) received PP only. Assessment of all participants in both groups A and B was carried out before and after the treatment program using numeric rating scale (NRS), The Oswestry Disability Index (ODI) and plasma cortisol level.
\end{abstract}

$\underline{\text { Results: }}$ There was a significant improvement in pain level, functional ability and plasma cortisol levels after treatment in each group and there was a significant difference between the two groups for the benefit to group (A).

Conclusion: "MET combined with PP demonstrate a significant difference in pain reduction and improvement of functional mobility in patients with post-partum coccydynia."

Keywords: Muscle Energy Technique (MET), phonophoresis, plasma cortisol level, post-partum, coccydynia

\section{Introduction}

Coccydynia is a painful condition in the coccyx region, The prevalence of coccydynia is unknown, It most commonly occurs in adolescents and adults, although children are sometimes affected $[1,6]$. It affects females five times more than males, the higher prevalence is thought to be due to injuries that occur during childbirth [1]. Its major cause is hypermobility of coccyx or its subluxation [2]. It occurs due to direct trauma on the coccyx, vaginal delivery [3] or unknown cause [4]. Most of the patients suffer from pain while sitting on a hard surface [5], which is exaggerated by rising from sitting [6].

Coccydynia, may be due to ligamentous traction with or without displacement of the coccyx or aggravation of a previous injury. Occasionally a coccyx may spontaneously fracture during the 2nd stage of labor. It can be a painful and incapacitating condition in the early post-partum period. It can interfere with the mother baby bonding process. The most common symptom is pain in the tail bone, the pain may be worsened in prolonged sitting position and with hip extension activities, such as stair climbing [7]. Oral analgesia may be ineffective and functional activities become intolerable [8].

There are a lot of recommended management techniques to relieve pressure on coccyx area and to reduce symptoms as: sitting posture through a cushion with cut out in the sacral support part, physical therapeutic pain control modalities and manual therapy techniques as manipulation and physiotherapy, 
analgesics as NSAID, local injections of corticosteroid, local anesthesia through injection of a numbing agent (Lidocaine) and steroid (to decrease inflammation) in the area surrounding the coccyx, where the physician uses imaging guidance to ensure that the injection is administered to the right area $[35,36]$. Most of the cases resolve within weeks to months with or without conservative treatment, but for a few patients, the pain can become chronic and debilitating [1]. If the symptoms persist and are not responsive to conservative management, coccygectomy is done as a surgical treatment [9] .

Therapeutic massage, cryotherapy, hot packs, ultrasound and myofascial release are some modalities in physiotherapy used for treatment of these cases [10] Cold produces vasodilatation which occurs later, and then the alternate flushing effect could usefully help to reduce pain. The circulatory effect of cold also has a beneficial effect on the rate of repair. Heat produces a hyperemia within the muscle which resolves the ischemia and reduce pain. Where pain is the result of nociceptors stimulation by the chemicals produced or released as a result of trauma or inflammation, a local increase in circulation could remove these chemicals and therefore reduce pain [37].

Phonophoresis (PP) is a non-invasive method of ultrasound application to deliver medications, usually topical analgesics or steroid, through the skin to deep tissues to relieve the pain. The curative effect of drug penetration varies due to some factors like rate, amount, actual drug penetration and skin depth $[11,12]$.

Dilek Durmus et al., [16] reported the effect of PP in chronic low back pain, they divided the participant into 3 groups: (1) exercise only, (2) US with exercise and (3) PP with exercise. The result showed improvement in all groups in pain and functional ability, but group 3 were statistically different compared to other groups.

Muscle Energy Technique (MET) is a manual therapy technique which uses voluntary contraction of a patient's muscle with a correctly controlled direction against a distinctly therapist counter-force [13]. Much research suggested using MET in the treatment of shortened muscles, muscle weakness, restricted joints and edema [13].

MET is one of the three most commonly used techniques applied by American Osteopaths in treatment. From the field of manual therapy, some studies have researched the effectiveness of MET and reported promising results. Given the fact that MET is a commonly applied therapeutic intervention, relevant and inexpensive. Health problems for which a true gold standard is lacking, and that there is some evidence of its effectiveness, the effort of a comprehensive systematic review seems warranted $[29,30]$.

MET is an effective conservative modality to alleviate lumbopelvic pain. The touch of the clinician, along with stimulation of agonist and antagonist muscles, seems to decrease perception of pain. This technique could be applied prior to other rehabilitation techniques, such as strengthening exercises, to decrease pain and enhance the effect of an applied exercise program. There are many advantages for applying
MET, one of which includes that it takes a very short time to be applied (less than 1 minute). It also allows the clinician to have physical contact with the patient. Lastly, MET is a low-force isometric contraction in a pain- free position. In conclusion, this technique is not painful or harmful to the patient [14]. The therapist provides resistive force counter to push patients' muscle contraction, aimed to help in restoring musculoskeletal functions [15].

Previous research has found that MET of the low back improved self-report of disability when used with supervised neuromuscular reeducation and resistance exercise training, but the effect of MET as an isolated treatment has not been determined [24].

Unfortunately, the literature review was unable to identify any study addressing the effect of MET in treating post-partum coccydynia. Consequently, the purpose of this study was to evaluate the effect of MET in treating such cases.

\section{Materials and method}

A prospective, randomized, parallel group, active controlled study with a 1:1 allocation ratio was conducted at the outpatient clinic of the Physiotherapy department, Faculty of Applied Medical Sciences, King Abdul-Aziz University, KSA from January to April 2016. The women participated in the study after signing an informed consent form before data collection.

\section{Participants}

\section{Inclusion criteria}

Forty volunteers, multi-parus female subjects suffering from coccydynia after six weeks post-partum. Their age ranged between $25-35$ years and BMI did not exceed $35 \mathrm{Kg} / \mathrm{m}^{2}$.

\section{Exclusion Criteria}

Patients suffering from any musculoskeletal disorder (Low back pain), neuromuscular disorders (Sciatica), (Lumbar disc prolapse) and gynaecological disorders (Genital prolapse).

The treatment course applied for patients lasted for 12 sessions (one every other day) 3 times per week.

\section{Randomization}

The women were randomly assigned to the treatment group $A(n=20)$ or the control group $B(n=20)$ by an independent person who selected numbers from sealed envelopes containing numbers chosen by a random number generator. The randomization was restricted to permuted blocks of different sizes to ensure that equal numbers were allocated to each group. The sequences assigned to the participants were placed in envelopes containing the allocation to each group A and B. An independent person who was blinded to the research protocol and not otherwise involved in the trial operated the random assignment.

\section{Study group (A)}

20 female patients were included in this group, their mean 
age (29.95 \pm 3.28$)$ years, their mean BMI $(28.11 \pm 4.23) \mathrm{kg} / \mathrm{m}^{2}$, and their mean of parity $(3.15 \pm 1.46)$. All received MET with a home programme and phonophoresis, 3 times per week for 12 sessions.

\section{Control group (B)}

20 female patients were included in this group, their mean age (30.20 \pm 3.24$)$ years, their mean BMI $(28.88 \pm 3.22) \mathrm{kg} / \mathrm{m}^{2}$, and their mean of parity $(3.70 \pm 1.46)$. All received phonophoresis 3 times per week for 12 sessions.

\section{Materials}

\section{Examination modalities}

Pain Assessment (Numeric Rating Scale (NRS)

The NRS for pain is a one-dimensional measure of pain intensity in adults, including those with chronic pain .It is an instrument tool to measure the intensity of pain, it consists an 11 -point numeric scale with 0 representing "no pain" and 10 representing extreme pain (Worst possible pain) [39] (Figure 1).

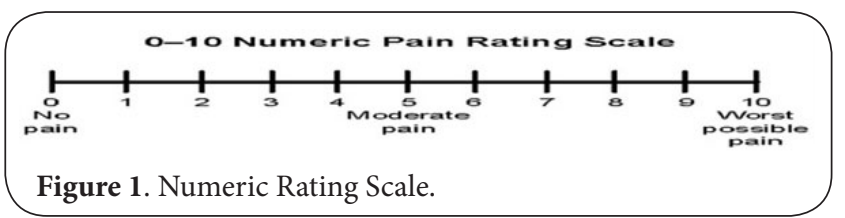

Functional ability assessment (The Oswestry Disability Index) (ODI)

The (ODI) has become one of the principal condition-specific outcome measures used in the management of spinal disorders. The ODI measures disability of the spine in a patient, using a 10 -item scale and these are evaluated by $0-5$ scores. The categories are pain severity, self-care, walking, sitting, standing, sexual function, travelling, and social life. The extreme score in ODI is 50, which means $100 \%$ disability. Every participant answered the ODI questionnaire before and after treatment to detect the level of functional disability. A higher score is usually associated with severe pain and debility. The ODI remains a valid and confident measure and has been a worthwhile outcome measure [33].

\section{Blood analysis (plasma cortisol level)}

The plasma cortisol concentration was significantly higher in pain patients as compared with healthy subjects free from pain at the time of the highest pain intensity. There is a positive correlation between the intensity of pain and increased plasma cortisol level (Damzal et al, 1983). Hence the assessment of plasma cortisol level was needed before and after the treatment to assess the decrease in the cortisol level as an indicator of improvement [38].

\section{Treatment modalities}

Ultrasound equipment

Ultrasound waves were applied with sodium diclofenac (Vol- taren Emulgel, Novartis) phonophoresis onto the painful side by the ultrasound device.

\section{Experimental procedures}

The explanation of the treatment was brief and clearly demonstrated to all the subjects in order to gain consent.

\section{Examination}

All the following assessment were done as mentioned above in the examination modalities part to all the subjects in both groups $(A)$ and $(B)$ before and after the treatment program

1. Pain Assessment (Numeric Rating Scale (NRS)

2. Functional ability assessment

3. Blood analysis (plasma cortisol level)

\section{Treatment}

The participant was asked to lie in the half lying position, with the back and arms well supported. The anticubital area was cleaned with alcohol. Blood sample of about $5 \mathrm{~cm}^{3}$ was drawn from the anticubital vein from all subjects by disposable sterile syringe by vein puncture to determine the plasma cortisol level, which was done in the biochemistry department. This was done 2 times, the first time before starting treatment and second after the end of treatment session. All samples are collected early at the morning before breakfast for all cases.

Study group (A) were treated by MET and sodium diclofenac (Voltaren Emulgel, Novartis) phonophoresis therapy through ultrasound device to allow penetration over the coccyx while the patient assuming a prone position. The parameters of ultrasound were $1 \mathrm{MHz}$ frequency for deep penetration, 1.5 $\mathrm{W} / \mathrm{cm}^{2}$ power, pulse ratio $50 \%$ for the greater mechanical compression and relaxation effects, duty-cycle continuous 1: 1 and, the treatment duration was for 5 minutes [34].

The MET was performed while the patient was lying supine on a treatment table, placing their buttocks just off the edge of the table with one leg placed on the therapist's shoulder and the other leg rested down under the therapist hand. The subject was asked to "push their leg into the therapist's shoulder" and "push up with the opposite leg into therapist's hand. A total of 5 contractions were resisted by a force equal to the subject's, held for 5 seconds with 5 seconds rest between each contraction [14].

Placement of subject during muscle energy technique: The leg of the anterior innominate was placed over the therapist shoulder and the leg of the posterior innominate was placed under the therapist hand. When an isometric contraction is produced, the anterior innominate will rotate posteriorly from the force of the hamstrings and the posterior innominate will rotate anteriorly from the force of the iliopsoas [14].

\section{Home exercises programme}

Following the MET procedure, the patient received a MET component to their home exercise program (HEP). This HEP is thought to assist the patient in maintaining spinal range 
of motion, thus decreasing the need for further MET corrections. For example, if a patient was diagnosed with a flexion and side-bending left restriction, the patient was instructed to place the left foot on a stool or chair (both hip and knee angles of $90^{\circ}$ ) and slowly bend forward and rotate to the left . Patients were instructed to stretch as far as possible in a painfree range and hold the stretch for 5 to 7 seconds. The patient was then instructed to place her hands upon the flexed knee to assist in returning to a standing position with the use of the upper extremities. Patients were to perform this stretch "as often as possible." [20]. Patients were asked to repeat the same steps for the right side. The patients were told to apply HEP for 3 repetitions on each side, 3 times every day, except the day of the clinical session. While the control group (B) was treated by phonophoresis only for $10 \mathrm{~min}$ \{as described before with group $(A)\}$.

\section{Statistical analysis}

Results are expressed as mean \pm standard deviation. Test of normality, Kolmogorov-Smirnov test, was used to measure the distribution of data measured pre-treatment. Accordingly, comparison between variables in the two groups was performed using either unpaired t-test (in normally distributed data) or Mann-Whitney test (in non-normally distributed data). Comparison between variables before and after treatment in the same group was performed using either paired t-test (in normally distributed data) or Wilcoxon Signed Ranks test (in non-normally distributed data). Statistical Package for Social Sciences (SPSS) computer program (version 21 windows) was used for data analysis. $P$ value $\leq 0.05$ was considered significant.

\section{Results \\ Participants' characteristics}

The demographic data of the participants of both groups revealed no significant difference between the two groups in terms of mean age, parity, and BMI ( $>0.05)$ (Table 1).

\section{Pain Assessment}

There was a significant decrease in pain intensity measured after treatment in both study (group A) $(1.75 \pm 0.85)$ and control (group B) $(6.10 \pm 1.52)$ when compared with their corresponding values measured before treatment ( $Z$-values $=-3.953$ and -3.754 , respectively; $p=0.001$ ). Also after treatment, there was a significant decrease in pain intensity in group $A$ when compared with group $B(Z$-value $=-5.438$ and $P$-value $=0.001)$ (Table 2).

\section{Functional ability}

There was a significant difference in the functional ability measured after treatment in both study (group A) $(6.90 \pm 3.82)$ and control (group B) $(19.65 \pm 4.64)$ when compared with their corresponding values measured before treatment ( $Z$ values $=-3.950$ and -3.924 , respectively; $p=0.001$ ). Also after treatment, there was a significant difference functional ability

Table 1. General characteristics of the participants in both groups A and B.

\begin{tabular}{llllll}
\hline & $\begin{array}{l}\text { Study group A } \\
(\mathbf{n = 2 0})\end{array}$ & $\begin{array}{l}\text { Control group B } \\
(\mathbf{n = 2 0})\end{array}$ & t value $^{\#}$ & P value & Significance \\
\hline Age $(\mathrm{yrs})$. & $29.95 \pm 3.28$ & $30.20 \pm 3.24$ & 0.242 & 0.810 & NS \\
BMI $\left(\mathrm{kg} / \mathrm{m}^{2}\right)$ & $28.11 \pm 4.23$ & $28.88 \pm 3.22$ & 0.648 & 0.521 & NS \\
No. of deliveries & $3.15 \pm 1.46$ & $3.70 \pm 1.46$ & 1.193 & 0.240 & NS \\
\hline
\end{tabular}

Data are expressed as mean \pm SD. $\#=$ unpaired $\mathrm{t}$-test. $\mathrm{NS}=\mathrm{p}>0.05=$ non-significant.

Table 2. Numeric Rating Scale in group A and B Pain Assessment.

Inter and intra-group comparison between mean values of pain in the two studied groups measured before and after treatment.

\begin{tabular}{llllll}
\hline & $\begin{array}{l}\text { Study group A } \\
(\mathbf{n = 2 0 )}\end{array}$ & $\begin{array}{l}\text { Control group B } \\
(\mathbf{n = 2 0 )}\end{array}$ & Z value $^{\#}$ & P value $^{\text {Significance }}$ \\
\hline Before treatment & $7.65 \pm 0.99$ & $8.15 \pm 0.93$ & -1.630 & 0.103 & $\mathrm{NS}$ \\
After treatment & $1.75 \pm 0.85$ & $6.10 \pm 1.52$ & -5.438 & 0.001 & $\mathrm{~S}$ \\
Mean difference & 5.90 & 2.05 & -- & -- & -- \\
\% change & $77.12 \downarrow \downarrow$ & $25.15 \downarrow \downarrow$ & -- & -- & - \\
Z value \#\# & -3.953 & -3.754 & -- & -- & -- \\
p value & 0.001 & 0.001 & -- & -- & - \\
Significance & $\mathrm{S}$ & $\mathrm{S}$ & -- & -- & -- \\
\hline
\end{tabular}

Data are expressed as mean \pm SD. \#=Mann-Whitney test. \#\#=Wilcoxon Sign Rank test. NS=p $>0.05$ $=$ non-significant. $\mathrm{S}=\mathrm{p}<0.05=$ significant. 
Embaby et al. Physical Therapy and Rehabilitation 2017,

in group $A$ when compared with group $B$ (Z-value $=(-5.224)$ and $P$-value $=0.001)($ Table 3$)$.

\section{Plasma cortisol level}

There was a significant decrease in Plasma cortisol level measured after treatment in both study (group A) $(5.09 \pm 1.12)$ and control (group B) $(8.86 \pm 0.94)$ when compared with their corresponding values measured before treatment ( $\mathrm{t}$-values= 11.889 and 4.093 , respectively; $p=0.001$ ). Also after treatment, there was a significant decrease in Plasma cortisol level for group $A$ when compared with group $B$ ( $t$-value $=11.507$ and P-value $=0.001)($ Table 4).

\section{Discussion}

Post-partum coccydynia is most commonly seen secondary to hormonal changes, which occur during the third trimester of pregnancy. These Changes induce a softening of the synchondrosis between the sacrum and coccyx, increases the mobility of the ligaments and surrounding muscles, causing inflammation [22].

This pain in the coccyx may radiate to hip and lumbar regions. The pain or tenderness may be aggravated by prolonged sitting, arising from seated position, leading back while seated, prolonged standing and walking, so the pain interferes with all the activity of the women, making it difficult for her even to sit to fed herself and her baby. Sometimes there is a pain with defecation or the patient feel a frequent need to defecate, the patient may feel pain during sexual intercourse or aggravated during menstruation and premenstrual period [22]. Unfortunately, the literature review was unable to identify any study addressing the effect of muscle energy technique in treating post-partum coccydynia. Consequently, the purpose of this study was to evaluate the effect of muscle energy technique in treating such cases.

The results of this study showed a significant improvement in pain level and functional ability in both groups $A$ and $B$. There was a significant difference between the two groups for the benefit to group (A). The study group (A) received MET with phonophoresis (PP) and home programme based on MET for four weeks, 3 sessions per week. The control group (B) received PP only for the same period of treatment.

The improvement in pain and function in the present study have several explanations as follows:

Table 3. Functional ability in group $A$ and $B$.

Inter and intra-group comparison between mean values of functional ability, in the two studied groups measured before and after treatment.

\begin{tabular}{llllll}
\hline & $\begin{array}{l}\text { Study group A } \\
(\mathbf{n}=\mathbf{2 0})\end{array}$ & $\begin{array}{l}\text { Control group B } \\
(\mathbf{n = 2 0})\end{array}$ & Z-value ${ }^{\#}$ & P-value & Significance \\
\hline Before treatment & $28.65 \pm 2.51$ & $29.65 \pm 1.60$ & -1.332 & 0.183 & $\mathrm{NS}$ \\
After treatment & $6.90 \pm 3.82$ & $19.65 \pm 4.64$ & -5.224 & 0.001 & $\mathrm{~S}$ \\
Mean difference & 21.75 & 10.0 & -- & -- & -- \\
\% change & $75.92 \downarrow \downarrow$ & $33.73 \downarrow \downarrow$ & -- & -- & -- \\
Z value $^{\# \#}$ & -3.950 & -3.924 & -- & -- & -- \\
p value & 0.001 & 0.001 & -- & -- & -- \\
Significance & $\mathrm{S}$ & $\mathrm{S}$ & -- & -- & -- \\
\hline
\end{tabular}

Data are expressed as mean \pm SD. \#=Mann-Whitney test. \#\#=Wilcoxon Sign Rank test.

$\mathrm{NS}=\mathrm{p}>0.05=$ non-significant, $\mathrm{S}=\mathrm{p}<0.05=$ significant

Table 4. Plasma cortisol levels in group $\mathrm{A}$ and $\mathrm{B}$.

Inter and intra-group comparison between mean values of plasma cortisol in the two studied groups measured before and after treatment.

\begin{tabular}{llllll}
\hline & $\begin{array}{l}\text { Study group A } \\
(\mathbf{n}=\mathbf{2 0})\end{array}$ & $\begin{array}{l}\text { Control group B } \\
(\mathbf{n = 2 0})\end{array}$ & $\begin{array}{l}\text { t-value } \\
\#\end{array}$ & P-value & Significance \\
\hline Before treatment & $9.86 \pm 1.61$ & $9.92 \pm 1.52$ & 0.132 & 0.896 & $\mathrm{NS}$ \\
After treatment & $5.09 \pm 1.12$ & $8.86 \pm 0.94$ & 11.507 & 0.001 & $\mathrm{~S}$ \\
Mean difference & 4.77 & 1.06 & -- & -- & -- \\
\% change & $48.38 \downarrow \downarrow$ & $10.69 \downarrow \downarrow$ & -- & -- & -- \\
t value \#\# & 11.889 & 4.093 & -- & -- & -- \\
p value & 0.001 & 0.001 & -- & -- & -- \\
Significance & $\mathrm{S}$ & $\mathrm{S}$ & -- & -- & -- \\
\hline
\end{tabular}

Data are expressed as mean \pm SD. \#=unpaired t-test. \#\#= paired t test. NS=p $>0.05=$ non-

significant. $S=p<0.05=$ significant 
Embaby et al. Physical Therapy and Rehabilitation 2017,

http://www.hoajonline.com/journals/pdf/2055-2386-4-5.pdf

doi: 10.7243/2055-2386-4-5

\section{Initially for MET}

The physiological mechanisms underlying the therapeutic effects of MET were unclear and may involve a variety of neurological and biomechanical mechanisms, including hypoalgesia, altered proprioception, motor programming and control, and changes in tissue fluid [26]. Lasting biomechanical changes to muscle property following MET have not been demonstrated, and changes to muscle extensibility and spinal range of motion may be related to mechanisms promoting hypoalgesia and an increase in stretch tolerance. Clinical studies suggest MET and related post-isometric techniques reduce pain and discomfort when applied to the spine or muscles [27]. MET may have physiological effects, regardless of the presence or absence of dysfunction [28].

Varghese [18], has stated that function of any articulation of the body which can be moved by voluntary muscle action, either directly or indirectly can be influenced by MET procedure, so this may stretch tight muscles, strengthen weak muscles and mobilize a restricted articulation. Also, the change in muscle expansibility may be due to the mechanism of analgesia and increase in stretch tolerance. When MET was applied with therapeutic exercise for more than one session, this may have greater effect on outcome [20].

Similarly the touch of the clinician, along with stimulation of agonist and antagonist muscles, seems to alter perception of pain. This technique could be performed prior to other rehabilitation techniques, such as strengthening exercises, to decrease pain and allow more efficient exercises to be executed. This technique may be better than others in decreasing pain for several reasons. The time it takes to administer MET is very short (less than 1 minute). It also allows the clinician to have physical contact with the patient, helping the patient to trust the clinician. Lastly, MET is a low-force isometric contraction in a pain-free position. This technique can be accomplished without causing further pain or harm to the patient [25].

MET aims to normalize soft tissue structures, such as shortened or tight muscles with no direct implication to the joint associated with these soft tissues. MET can be used to improve joint mobility by influencing the dysfunctional soft tissues. MET can be used to relax tight, tense musculature, spasms, or fibrotic changes due to chronic soft tissue problems [31]. MET has several uses that can help increase muscle strength, increase range of motion (ROM), and decrease edema [32].

MET was used as a common conservative treatment and a gentle manual therapy for restricted motion of the spine and extremities for pathology around the spine, particularly lumbopelvic pain $[19,20,23]$.

Next, Phonophoresis (PP) is the use of therapeutic ultrasound to increase percutaneous drug absorption [40]. This method allows suitable and fast concentration of drug in the tissues without side effects, the drug is applied direct at the site and massaged with a therapeutic ultrasound applicator. Ultrasound has two modes: continuous and pulsed output. The continuous mode has thermal effects, and the pulsed mode which is used in this study has mechanical effects such as cavitation (creation of tiny air bubbles by splitting molecules within keratinocytes through the use of ultrasound), microstreaming, acoustic streaming, increased skin pore size and intercellular space [41].

The small cavitation bubbles, which fluctuate in a steady manner, generate mechanical stress in the near blood vessels without causing any damage in tissue and increase penetration of vessels structurally and physiologically [42].

Thus, Phonophoresis (PP) Help in penetrating the gel inside the body because it increases cell permeability through the mechanical effect. In addition to the effect of sodium diclofenac gel which is used as anti-swelling, anti-inflammatory and pain- relieving [21].

Further researches are needed to compare the effects of MET to other treatment modalities, also more studies are needed to compare the long term effects of different treatment modalities on coccydenia cases for both the conservative and surgical treatment modalities.

\section{Limitations}

1. Lack of previous studies that used MET with coccydenia cases

2. We could not isolate the pure effect of MET alone in this study as it was used with phonophoresis.

3. Restrictions of the Saudi community to take any photos to female patients, as it was not allowed and refused also by participants, that is why we did not add any photos to the exercise procedures.

\section{Conclusion}

The MET was effective, more comfortable, and safe for the treatment of post-partum coccydynia. There was a statistically significant reduction in pain intensity and functional ability. Accordingly, it was found that MET in conjunction with phonophoresis to be an effective, noninvasive, cheap, and safe method of relieving post-partum coccydinia.

\section{Competing interests}

The authors declare that they have no competing interests.

\section{Authors' contributions}

\begin{tabular}{|l|c|c|c|}
\hline Authors' contributions & HE & SE & MEH \\
\hline Research concept and design & $\checkmark$ & -- & -- \\
\hline Collection and/or assembly of data & $\checkmark$ & -- & -- \\
\hline Data analysis and interpretation & $\checkmark$ & -- & -- \\
\hline Writing the article & $\checkmark$ & $\checkmark$ & $\checkmark$ \\
\hline Critical revision of the article & -- & $\checkmark$ & $\checkmark$ \\
\hline Final approval of article & $\checkmark$ & $\checkmark$ & $\checkmark$ \\
\hline Statistical analysis & -- & $\checkmark$ & $\checkmark$ \\
\hline
\end{tabular}

\section{Acknowledgements}

The great assistance and participation of Walaa Gharawi and Samia Jamal, graduates of Physical Therapy Department, Faculty of Applied Medical Sciences, King Abdul-Aziz University, are much appreciated. Many thanks, to all patients 
Embaby et al. Physical Therapy and Rehabilitation 2017,

who participated in this study for their co-operation.

Publication history

Editor: Gordon John Alderink, Grand Valley State University, USA.

Received: 27-Mar-2017 Final Revised: 10-Jun-2017

Accepted: 28-Jul-2017 Published: 10-Aug-2017

\section{References}

1. Lirette LS, Chaiban G, Tolba R and Eissa H. Coccydynia: an overview of the anatomy, etiology, and treatment of coccyx pain. Ochsner J. 2014; 14:84-7. | PubMed Abstract | PubMed FullText

2. Patel R, Appannagari A and Whang PG. Coccydynia. Curr Rev Musculoskelet Med. 2008; 1:223-6. | Article | PubMed Abstract | PubMed FullText

3. Waldman D. Coccydynia. Atlas of Common Pain Syndromes. 2nd ed. Philadelphia: Elsevier. 2012; 100-114.

4. Hodges SD, Eck JC and Humphreys SC. A treatment and outcomes analysis of patients with coccydynia. Spine J. 2004; 4:138-40. | Article | PubMed

5. Thiele GH. Coccygodynia: Cause and Treatment. Dis Colon Rectum. 1963; 6:422-36. I PubMed

6. Fogel GR, Cunningham PY, 3rd and Esses SI. Coccygodynia: evaluation and management. J Am Acad Orthop Surg. 2004; 12:49-54. | Article | PubMed

7. Brandom J. Bankouski M, Amy E and Hearne D. Chronic pelvic pain. In: The Johns Hopkins Manual of Gynaecology and Obstetrics. 2nd ed., Chapter 26, Awolters Keuwer Company, Philadelphia. 2002; 318-330.

8. Sapsford, L., Bullock-Sextan, S. and Markwell, P. Post natal management. In: Women's health a text book for physiotherapists, 1st ed., chapter 19, WB Saundners company Ltd, London; 1998; 234-240.

9. Karadimas EJ, Trypsiannis G and Giannoudis PV. Surgical treatment of coccygodynia: an analytic review of the literature. Eur Spine J. 2011; 20:698-705. | Article | PubMed Abstract | PubMed FullText

10. Micheo W. Rehabilitation Medicine Quick Reference. Musculoskeletal, Sports and Occupational Medicine. New York, US: Demos Medical . 2010; 60-1.

11. Durmus D, Alayli G, Tufekci T and Kuru O. A randomized placebocontrolled clinical trial of phonophoresis for the treatment of chronic neck pain. Rheumatol Int. 2014; 34:605-11. | Article | PubMed

12. Polat $B E$, Hart $D$, Langer $R$ and Blankschtein D. Ultrasound-mediated transdermal drug delivery: mechanisms, scope, and emerging trends. J Control Release. 2011; 152:330-48. | Article | PubMed Abstract | PubMed FullText

13. Franke H, Fryer G, Ostelo RW and Kamper SJ. Muscle energy technique for non-specific low-back pain. Cochrane Database Syst Rev. 2015; CD009852. | Article | PubMed

14. Selkow NM, Grindstaff TL, Cross KM, Pugh K, Hertel J and Saliba S. Shortterm effect of muscle energy technique on pain in individuals with non-specific lumbopelvic pain: a pilot study. J Man Manip Ther. 2009; 17:E14-8. | Article | PubMed Abstract | PubMed FullText

15. Fryer G. Muscle energy technique: An evidence-informed approach. International Journal of Osteopathic Medicine. 2011; 14:3-9.

16. Durmus D, Alayli G, Goktepe AS, Taskaynatan MA, Bilgici A and Kuru O. Is phonophoresis effective in the treatment of chronic low back pain? A single-blind randomized controlled trial. Rheumatol Int. 2013; 33:173744. | Article | PubMed

17. Franke H, Fryer G, Ostelo RW and Kamper SJ. Muscle energy technique for non-specific low-back pain. Cochrane Database Syst Rev. 2015; CD009852. | Article | PubMed

18. Varghese S. A Study On The Effectiveness Of Muscle Energy Technique (Met) As Compared To Manuplationtherapy In Chronic Low Back Pain. International Journal of Latest Research in Science and Technology. 2012; 1:214-219.

19. El-Bandrawy A and Mamdouh A. Effect of Muscle Energy Technique on
Pain Perception and Functional Disability of Women with Postnatal Low Back Pain. British Journal of Medicine and Medical Research. 2014; 4:5253-61.

20. Wilson E, Payton O, Donegan-Shoaf L and Dec K. Muscle energy technique in patients with acute low back pain: a pilot clinical trial. $J$ Orthop Sports Phys Ther. 2003; 33:502-12. | Article | PubMed

21. Ay S, Dogan SK, Evcik D and Baser OC. Comparison the efficacy of phonophoresis and ultrasound therapy in myofascial pain syndrome. Rheumatol Int. 2011; 31:1203-8. | Article | PubMed

22. Cooper D, Mike S, Lee M, Oregory E and Lutz S. Fracture of coccyx during childbirth: a case report of an unusual cause of coccygodynia. Archives of Physical Medicine and Rehabilitation. 2003; 84:315-322.

23. Lenehan KL, Fryer $G$ and McLaughlin P. The effect of muscle energy technique on gross trunk range of motion. J Osteopath Med. 2003; 6:13-18.

24. Wilson $E$, Payton O, Donegan-Shoaf $L$ and Dec K. Muscle energy technique in patients with acute low back pain: a pilot clinical trial. $J$ Orthop Sports Phys Ther. 2003; 33:502-12. | Article | PubMed

25. Selkow NM, Grindstaff TL, Cross KM, Pugh K, Hertel J and Saliba S. Shortterm effect of muscle energy technique on pain in individuals with non-specific lumbopelvic pain: a pilot study. J Man Manip Ther. 2009; 17:E14-8. | Article | PubMed Abstract | PubMed FullText

26. Fryer $\mathrm{G}$ and FossumC. Therapeutic mechanisms underlying muscle energy approaches. In: Fernandez-de-las-Penas C, Arendt-Nielsen Lars, Gerwin R D editor(s). Tension-Type and Cervicogenic Headache: Pathophysiology, Diagnosis, and Management. Sudbury, MA: Jones and Bartlett Publishers; 2010.

27. Wilson E, Payton O, Donegan-Shoaf L and Dec K. Muscle energy technique in patients with acute low back pain: a pilot clinical trial. $J$ Orthop Sports Phys Ther. 2003; 33:502-12. | Article | PubMed

28. Fryer $\mathrm{G}$ and Ruszkowski W. The influence of contraction duration in muscle energy technique applied to the atlantoaxial joint. J Osteopath Med. 2004; 7:79-84.

29. Johnson SM and Kurtz ME. Osteopathic manipulative treatment techniques preferred by contemporary osteopathic physicians. J Am Osteopath Assoc. 2003; 103:219-24. | Article | PubMed

30. Selkow NM, Grindstaff TL, Cross KM, Pugh K, Hertel J and Saliba S. Shortterm effect of muscle energy technique on pain in individuals with non-specific lumbopelvic pain: a pilot study. J Man Manip Ther. 2009; 17:E14-8. | Article | PubMed Abstract | PubMed FullText

31. Chaitow L. Muscle Energy Techniques. Philadelphia, PA: Churchill Livingstone; 3rd ed. 2006.

32. Greenman P. Principles of Manual Medicine. Philadelphia, PA: Lippincott, Williams, and Wilkins; 3rd ed. 2003.

33. Fairbank JC. Oswestry disability index. J Neurosurg Spine. 2014; 20:23941. | Article | PubMed

34. Bradnock S and Ross L. Long wave therapy in the treatment of acute ankle sprains. Physiotherapy.1996; 61:78-84.

35. Wray CC, Easom S and Hoskinson J. Coccydynia. Aetiology and treatment. J Bone Joint Surg Br. 1991; 73:335-8. | Article | PubMed

36. Andrew J, Cale D, Stanley A and Herring M.D. Clinical Presentation and Diagnosis subsets. Low back pain handbook, A guid for the practicing clinician, $2^{\text {nd }}$ ed., Chapter 4, Hanley \& Belfus, Inc. Philadelphia, 2003; 112-130.

37. Wells A, Frampton P and Bousher D. Heat and cold in: pain management by physiotherapy. $2^{\text {nd }}$ ed., chapter 16 , Butterworth Heinemann, phyladelphia. 1994; 178-184.

38. Damzal T, Szczdlik A, Kwasucki J, Zaleska B and Lypka A. The relationship between plasma cortisol level and acute trauma, Pain. 1983; 17:67-70.

39. Hawker GA, Mian S, Kendzerska T and French M. Measures of adult pain: Visual Analog Scale for Pain (VAS Pain), Numeric Rating Scale for Pain (NRS Pain), McGill Pain Questionnaire (MPQ), Short-Form McGill Pain Questionnaire (SF-MPQ), Chronic Pain Grade Scale (CPGS), Short Form-36 Bodily Pain Scale (SF-36 BPS), and Measure of Intermittent and Constant Osteoarthritis Pain (ICOAP). Arthritis Care Res (Hoboken). 2011; 63 Suppl 11:S240-52. | Article | PubMed 
Embaby et al. Physical Therapy and Rehabilitation 2017,

http://www.hoajonline.com/journals/pdf/2055-2386-4-5.pdf

40. Silveira PC, Victor EG, Schefer D, Silva LA, Streck EL, Paula MM and Pinho RA. Effects of therapeutic pulsed ultrasound and dimethylsulfoxide (DMSO) phonophoresis on parameters of oxidative stress in traumatized muscle. Ultrasound Med Biol. 2010; 36:44-50. | Article | PubMed

41. Low J RA. "Electrotherapy explained: principles and practice." 3rd ed. Oxford: Butterworth-Heinemann; 2001.

42. Hynynen K. Focused ultrasound for blood-brain disruption and delivery of therapeutic molecules into the brain. Expert Opin Drug Deliv. 2007;

4:27-35. | Article | PubMed

\section{Citation:}

Embaby $\mathrm{H}$, Elgendy $\mathrm{S}$ and Hasanin ME. Effect of muscle energy technique in treating post-partum coccydynia: A randomized control trial. Phys Ther Rehabil. 2017; 4:5.

http://dx.doi.org/10.7243/2055-2386-4-5 